\title{
MECHANISMS CONTROLLING CATION CONCENTRATIONS IN THE HUMAN CELL: EVIDENCE FROM THE EFFECT OF IODOACETATE ON NA AND K EXCHANGE RATES OF THE ERYTHROCYTE ${ }^{1}$
}

\author{
By W. D. LOVE, J. A. CRONVICH, AND G. E. BURCH \\ (From the Department of Medicine and the Department of Electrical Engineering of the Tulane \\ University of Louisiana, and the Charity Hospital of Louisiana at New Orleans)
}

(Submitted for publication August 5, 1954; accepted September 7, 1954)

The mechanisms controlling intracellular electrolyte content are of clinical interest because abnormalities of intracellular electrolyte distribution occur in a variety of illnesses. Tissue electrolyte metabolism can be investigated by the direct study of muscle removed by biopsy, or by the use of balance technics from which deductions about changes in the quantity of intracellular electrolyte are made. However, neither of these methods is suited for extensive clinical application. Therefore, the readily obtainable circulating erythrocytes (RBC) have been studied with the hope that they would prove to be sufficiently similar to the bulk of body cells in their metabolism to reflect the intracellular electrolyte state of the body as a whole. Reports of abnormalities in the $\mathrm{Na}$ and $\mathrm{K}$ content of $\mathrm{RBC}$ in association with disease have appeared (1-4), but proof of a parallel relationship between the changes in RBC and those in other cells is not yet available. Like other human cells, the erythrocytes of man contain a high concentration of potassium and a low concentration of sodium, despite the continuous exchange of both of these cations between the cells and plasma (5-11). It has been maintained that active mechanisms exist in the erythrocyte for the inward transport of potassium and for the expulsion of sodium against the concentration gradients and that these processes are energized by glycolysis (11-13). The experiments reported herein were conducted to test this hypothesis.

Iodoacetate, which is known to abolish glycolysis and selective cation accumulation in erythrocytes (14), was added to human whole blood maintained under simulated physiologic conditions in vitro. By the use of $\mathrm{Na}^{22}, \mathrm{~K}^{42}$, and $\mathrm{Rb}^{88}$, the

1 Aided by a Public Health Service grant H-143, U. S. A. E. C. Grant No. AT-(40-1)-233, and the Mrs. E. J. Caire Fund for Research in Heart Disease. changes in the rates with which $\mathrm{Na}$ and $\mathrm{K}$ entered and left the RBC were measured. If iodoacetate abolished the active processes postulated to exist in the RBC, the expected result would be decreases in the rates of entry of potassium and exit of sodium.

\section{METHODS}

The methods employed in these studies have been described in detail elsewhere (8-10). Heparinized human blood was placed in paraffined flasks and gently agitated at $38^{\circ} \mathrm{C}$. Na-mono-iodoacetate in a final concentration of $10^{-6} \mathrm{M}$ was added fifteen minutes before the isotopes. The rate at which sodium entered the $R B C$ was measured by adding $\mathrm{Na}^{2}$ to the plasma and following the rise of specific activity in the erythrocytes with time. The rate of return of sodium from the erythrocytes to the plasma was considered to be equal to the difference between the rate of entry of sodium into the cells and the rate of change in total sodium content of the erythrocytes. In three experiments $\mathrm{Rb}^{*}$ was used to trace potassium by the method discussed elsewhere (10). $\mathrm{Rb}^{*}$ was shown to be utilized by normal $\mathrm{RBC}$ in vitro in a manner that is quantitatively and qualitatively very similar to that of potassium. In fact, by the methods used, no difference in their behavior in normal cells was detected. Figure 1 shows that this similarity of behavior is also present in $\mathrm{RBC}$ under the influence of iodoacetate. By measuring changes in "specific activity" ( $\mathrm{Rb}^{\star}$ cpm. per mEq. $\mathrm{K}^{\infty}$ as well as $\mathrm{K}^{\omega} \mathrm{cpm}$. per $\mathrm{mEq}$. $\left.K^{\infty}\right)$ of plasma and erythrocytes, the rates of potassium intake and output by the RBC were both observed directly. The radioactivity was measured with a thin, mica end-window G. M. tube. Sodium and potassium were determined with a modified Beckman model $D$. U. flame photometer, making empirical corrections for mutual excitation of sodium and potassium. The erythrocytes were separated from the plasma by means of a special clamp which allowed RBC centrifuged in plastic tubes to be isolated with an estimated plasma content of 1.9 per cent (8). Serial determinations of hematocrit in three experiments revealed no significant change in RBC volume up to seven hours after adding iodoacetate.

Calculations of exchange rate were made by the method of Sheppard and Martin (5), assuming that RBC and 
plasma form two uniformly mixed communicating compartments. Since the rates of transfer into and out of the RBC were not equal and the contents of the compartments were changing in a reciprocal fashion, rates were calculated from hour to hour using the following formulae of Sheppard:

$$
\begin{aligned}
& \frac{d S_{21}}{d t}=\frac{S_{2} \cdot \frac{d a_{2}}{d t}}{a_{1}-a_{2}} \\
& \frac{d S_{12}}{d t}=\frac{S_{1} \cdot \frac{d a_{1}}{d t}}{a_{2}-a_{1}}
\end{aligned}
$$

where

$\frac{d S_{21}}{d t}$ and $\frac{d S_{12}}{d t}$ are respectively the rates of transfer of nontracer material into and out of the RBC,

$S_{1}$ and $S_{2}$ are the total nontracer sodium or potassium content of the plasma and $\mathrm{RBC}$ respectively, and

$a_{1}$ and $a_{2}$ are the specific activities of plasma and RBC respectively $\left(\mathrm{Na}^{22} / \mathrm{Na}^{23}, \mathrm{Rb}^{86} / \mathrm{K}^{39}\right.$, or $\left.\mathrm{K}^{12} / \mathrm{K}^{39}\right)$.

$\frac{d a_{1}}{d t}$ and $\frac{d a_{2}}{d t}$ were determined graphically from observed data.

Since approximately two-thirds of the RBC sodium exchanges with the plasma in one hour, RBC sodium specific activity rapidly approached that of the plasma. When the difference between their specific activities became small, small errors in the determination of specific ac- tivity in either compartment made large percentile errors in the absolute difference between them. Since these errors were not necessarily random ones that would be subject to statistical treatment, calculations of exchange rate have not been reported when $R B C$ specific activity had reached three-fourths of the plasma specific activity.

\section{RESULTS}

\section{Changes in $R B C N a$ and $K$ concentrations after addition of iodoacetate}

In each experiment there was a nearly linear rise in $\mathrm{RBC}$ sodium content after addition of iodoacetate to the whole blood, the mean rate of increase in RBC sodium concentration being 1.18 mEq. Na per L. RBC per hr. (Figure $2 b$ ). The rate of fall in $R B C$ potassium was greater than the rate of gain of sodium, averaging $1.80 \mathrm{mEq}$. $\mathrm{K}$ per L. RBC per hr. when measured directly (Figure 2c) and $1.67 \mathrm{mEq}$. $K$ per $\mathrm{L}$. RBC per hr. when determined from the rise in plasma potassium, which is expressed as $\mathrm{mEq}$. per L. RBC present in the whole blood (Figure 2a). These net transfers of sodium and potassium began in less than one hour after adding iodoacetate.

\section{COMPARISON OF $K^{* 2}$ AND Rb ${ }^{* 6}$ INTAKE OF ERYTHROCYTES TREATED WITH IODOACETATE}

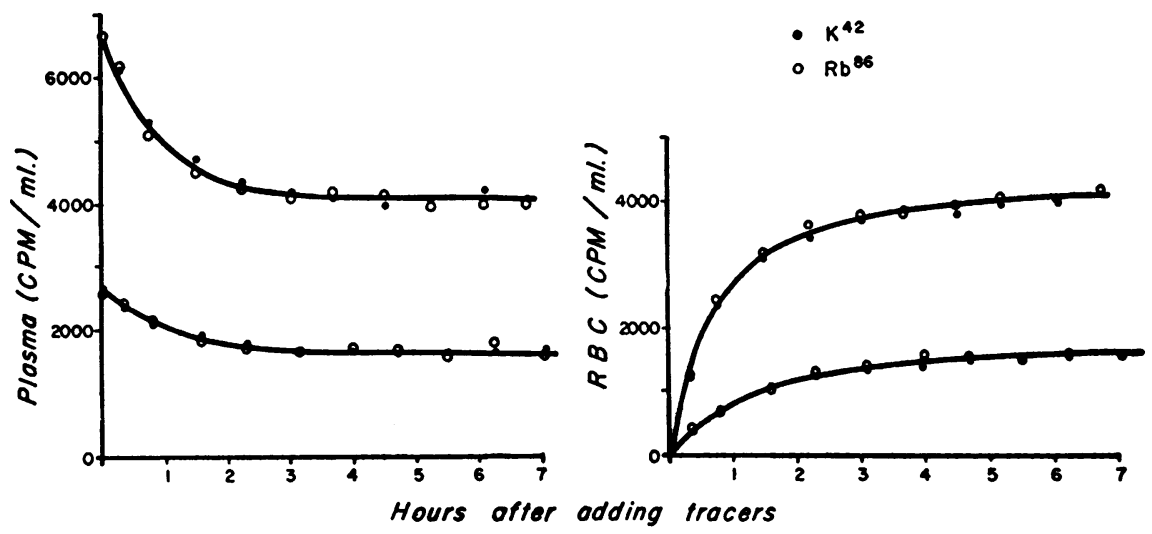

Fig. 1. Comparison of the Intake of $\mathrm{K}^{\star}$ and RB" by RBC in Two Specimens of Human Whole BloOd AT $38^{\circ}$ C. In Vitro

Iodoacetate $\left(10^{-8} \mathrm{M}\right)$ was added 15 minutes before the isotopes. The differences in counting levels are caused by the addition of unequal amounts of tracers in the two instances. 


\section{CHANGES IN PLASMA $K$ AND ERYTHROCYTE No AND $K$ AFTER THE ADDITION OF IODOACETATE TO WHOLE BLOOD}

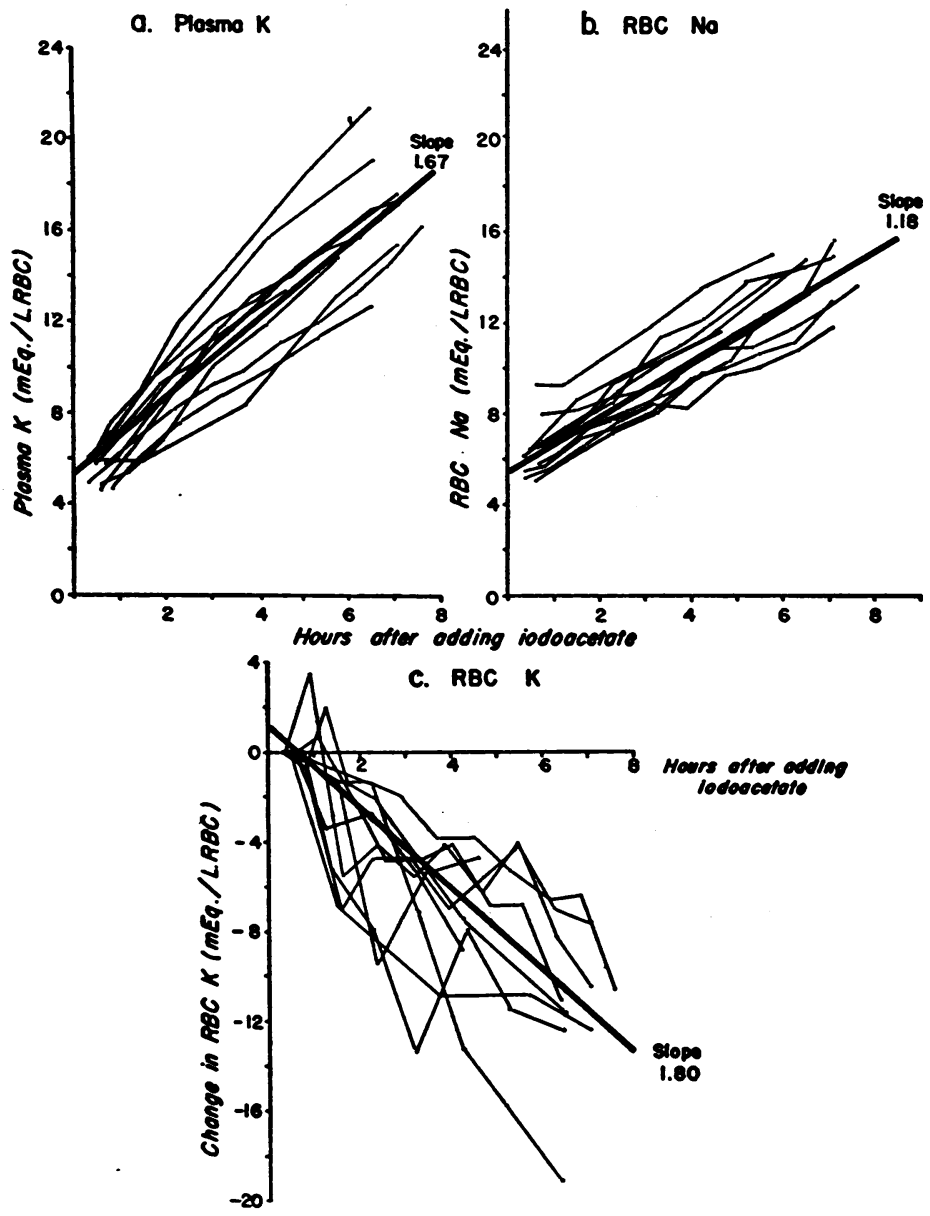

Fig. 2. The Thme Course of the Rise in Plasma Potassium (a) and Erythrocyte Sodium (b) after the AdDition of Iodoacetate $\left(10^{-6} \mathrm{M}\right)$ to Human Whole Blood at $38^{\circ}$ C. In Vitro

The fall in RBC potassium is shown in (c). Plasma potassium is expressed as mEq. per. L. RBC. The regression lines calculated by the method of least squares are indicated.

\section{Influence of iodoacetate on $R B C$ sodium exchange rates}

In Figure 3a the rate of intake of sodium by normal cells in three instances is compared to the rate of intake by the cells in two determinations in which iodoacetate was added. Figures $3 b, c$, and $d$ show the same comparison made from simultaneous determinations on aliquots of the same blood samples. There is no evidence in these data of an increase in the rate of intake of sodium after the addition of iodoacetate. There- fore, since the sodium content of the iodoacetatetreated cells was increasing at an average rate of $1.18 \mathrm{mEq}$. Na per L. RBC per hr., the rate of output of sodium from them must have been less than in the controls. In the experiment illustrated in Figure 3d, three and one-half hours after the addition of $\mathrm{Na}^{22}$ the blood was lightly centrifuged and the plasma was replaced with tracer-free plasma. This allowed the direct determination of the rates of both intake and output of sodium by these cells as the $\mathrm{Na}^{22}$ flowed out of them. These rates are indicated in Figures $3 e$ and $f$. Again the 
intake rate was similar in control and iodoacetatetreated blood; and the output rate of the iodoacetate-treated cells was low, confirming the previous inference from intake rate and net change in sodium content.

\section{Influence of iodoacetate on $R B C$ potassium ex- change rates}

Figure 4 summarizes the results of determinations of the time course of the rates of intake and output of potassium by RBC after the addition of iodoacetate. In each experiment a simultaneous control was carried out on an aliquot of the same blood sample. In three experiments with iodoacetate $R b^{86}$ was the tracer, and in two others $R b^{86}$ and $\mathrm{K}^{\mathbf{4 2}}$ were used simultaneously. The results were essentially the same in all cases. The data show that during the first hour after addition of iodoacetate there was a rise in the rate with which potassium left the cells and that later this returned to the level of the controls. The intake rate declined until the third or fourth hour, and thereafter was maintained at a low rate.

\section{DISCUSSION}

Comparison of these data with the previously reported results of others is difficult because of the wide variation in experimental conditions under which erythrocyte sodium and potassium exchange have been measured. Harris and Maizels have determined the effect of $\mathrm{NaF}$ on the sodium exchange of RBC collected several hours or longer before the measurements, which were carried out after suspension of the cells in a large volume of aqueous electrolyte solution (15). They found that $\mathrm{NaF}$, an inhibitor of glycolysis, essentially abolishes the movement of sodium out of the red cells, while affecting intake little. However, the

\section{EFFECT OF IODOACETATE ON ERYTHROCYTE INTAKE AND OUTPUT RATES OF NO}

a. Intake

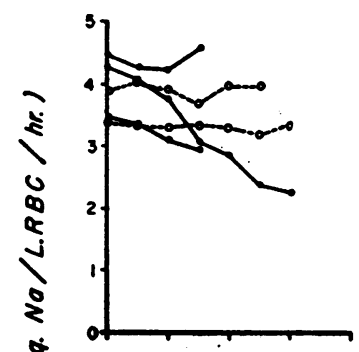

b. Intake

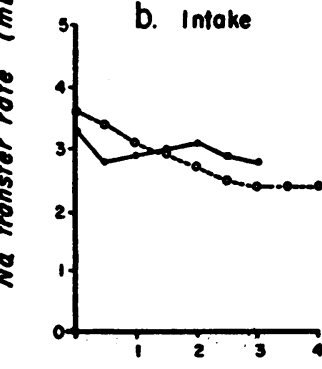

C. Intoke

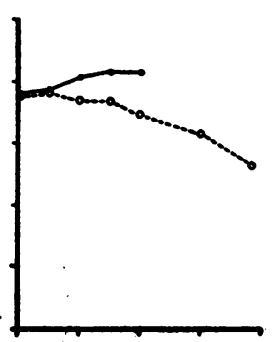

d. Intake e. Intoke
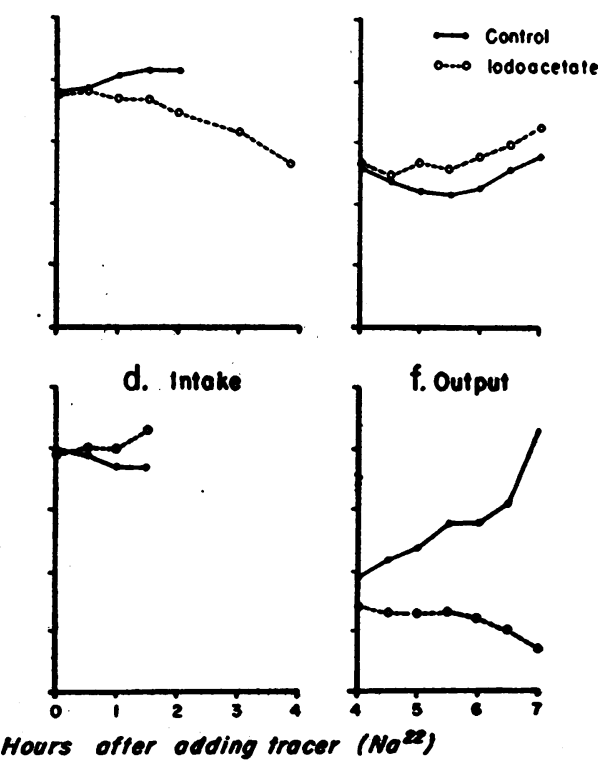

Fig. 3. Na Irtake and Output Rates of Control and of Iodoacerate-Treated RBC

a. $\mathrm{Na}$ intake in three controls compared with that in two measurements on iodoacetatetreated cells.

b, $c$, and $\mathrm{d}$. Simultaneous measurements of $\mathrm{Na}$ intake in control and iodoacetate-treated cells from the same blood samples.

e and f. $\mathrm{Na}$ intake and output rates of the cells illustrated in (d), measured from four to seven hours after adding $\mathrm{Na}^{2}$. The original plasma was replaced by tracer-free plasma after three and one-half hours of incubation. 


\section{EFFECT OF IODOACETATE ON ERYTHROCYTE INTAKE AND OUTPUT RATES OF K}

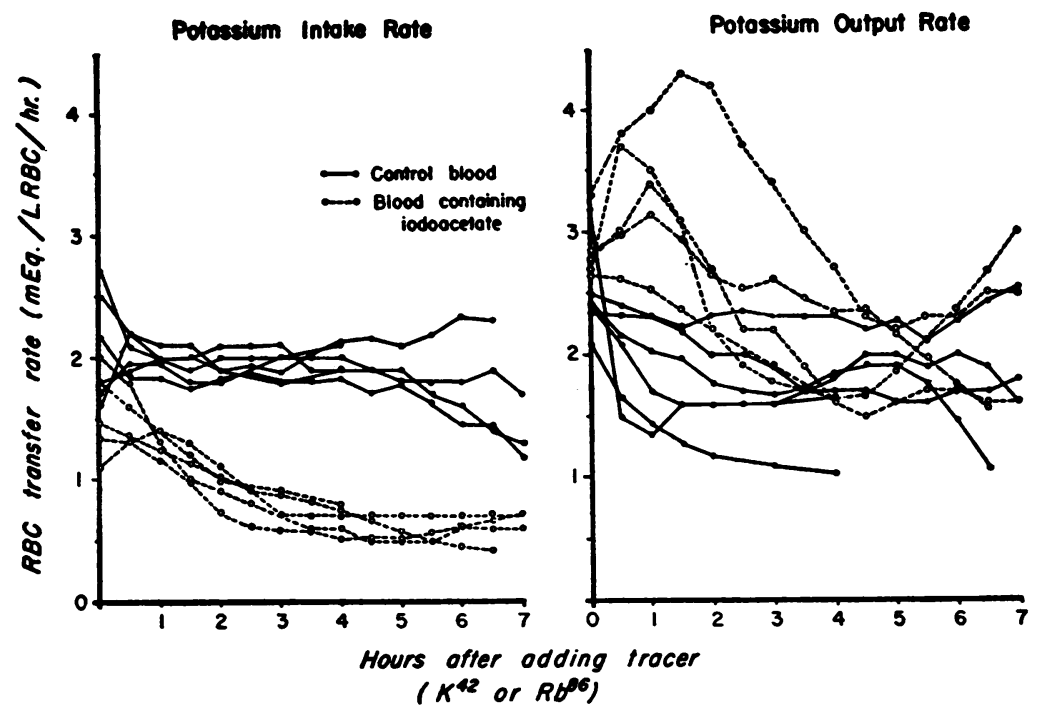

Fig. 4. The Efrect of Iodoacetate on RBC Intake and OUtput Rates of $\mathbf{K}$

In each experiment in which iodoacetate was added, $\mathrm{K}$ exchange rates were measured simultaneously on an aliquot of the same blood without iodoacetate.

fractional exchange of sodium by $\mathrm{RBC}$ under these conditions was only one-third to one-half of that observed in freshly obtained cells incubated in plasma. The experiments reported herein show that at the higher exchange rates present under more nearly physiologic conditions the inhibition of glycolysis by iodoacetate results in a reduction of only one-third in the sodium output rate.

Taylor, Weller, and Hastings have reported measurements of $\mathrm{K}$ exchange rates in the presence of $\mathrm{NaF}$ (16). In their method fresh cells are incubated in an inorganic medium containing glucose. Under these conditions the $K$ exchange rate was essentially the same as that observed in plasma. The initial entry rate was determined from the initial slope of the curve of loss of "plasma" $\mathrm{K}^{42}$. The exit rate was equal to the sum of the initial entry rate and the rate of net loss of RBC potassium. They reported that the rate of entry was decreased by 60 per cent and the rate of exit increased by 75 per cent. Eckel, in experiments carried out by similar technics, has likewise reported an accelerated output rate, although the increase was six to twelve times the normal rate (17). However, in his results an increase in the intake rate proportional to the rise in concentration of plasma $\mathrm{K}$ was present. It is perhaps pertinent that Sheppard and Beyl, using similar methods but incubating the cells in plasma, have found that the loss of potassium by RBC injured by large doses of $x$-rays is caused by an increase in the rate of movement of potassium from cells to plasma with essentially unaltered movement of potassium from plasma to cells (18).

Solomon has analyzed the processes responsible for sodium and potassium exchange in the $\mathrm{RBC}$ from the thermodynamic viewpoint (11). He considers that the available data show that sodium and potassium are transported into the cell by different mechanisms, that the processes responsible for the entry and exit of sodium are different, and that potassium influx and outflux are probably not affected by the same process either. This latter conclusion is supported by the report of Taylor, Weller, and Hastings that cholinesterase inhibitors cause loss of RBC potassium by decreasing the intake rate, whereas choline acetylase inhibitors cause a loss of potassium by increasing the output rates (16). Solomon concludes that in RBC neither sodium nor potassium is transported in either direction by a process like simple diffusion. However, Cooke and Segar have recently postulated a mechanism for controlling muscle electrolyte composition which involves pas- 
sive diffusion as the phenomenon responsible for loss of potassium from the cell and movement of sodium into the cell, with the reverse processes being performed by a system with properties like an exchange resin (19). Harris has postulated that in RBC there are both active and passive components of the influx and outflux of both sodium and potassium (13).

From consideration of what is known about the process of cation exchange in human $\mathrm{RBC}$, there is little reason to predict that simple mechanisms are responsible. The evidence favors the existence of a complex system of vital processes, with the cellular cation concentrations being determined by the dynamic equilibrium resulting from their interaction.

\section{SUM MARY}

Following the inhibition of glycolysis in human erythrocytes by Na-mono-iodoacetate there was a net flow of sodium into the cells $(1.18 \mathrm{mEq}$. $\mathrm{Na}$ per L. RBC per hr.) and a greater flow of potassium out of them (1.80 mEq. K per L. RBC per hr.). Determination of sodium and potassium exchange rates by the use of radioisotopes showed that the net gain of sodium was caused by a decrease in sodium output with the intake being little affected; whereas, the loss of potassium was caused by both an increase in output and a decrease in intake.

These results confirm the presence of active governing processes in $\mathrm{RBC}$ which promote the intake of potassium and the output of sodium and inhibit the output of potassium.

\section{REFERENCES}

1. Hutt, M. P., Effect of disease on erythrocyte and plasma potassium concentrations. Am. J. M. Sc., 1952, 223, 176.

2. Lans, H. S., Stein, I. F., Jr., and Meyer, K. A., The relation of serum potassium to erythrocyte potassium in normal subjects and patients with potassium deficiency. Am. J. M. Sc., 1952, 223, 65.

3. Harrison, H. E., Finberg, L., and Fleishman, E., Disturbances of ionic equilibrium of intracellular and extracellular electrolytes in patients with tuberculous meningitis. J. Clin. Invest., 1952, 31, 300.

4. Etteldorf, J. N., and Overman, R. R., Plasma and erythrocytic ion concentrations in infant diarrhea. Federation Proc., 1950, 9, 39.
5. Sheppard, C. W., and Martin, W. R., Cation exchange between cells and plasma of mammalian blood. I. Methods and application to potassium exchange in human blood. J. Gen. Physiol., 1950, 33, 703.

6. Sheppard, C. W., Martin, W. R., and Beyl, G., Cation exchange between cells and plasma of mammalian blood. II. Sodium and potassium exchange in the sheep, dog, cow, and man and the effect of varying the plasma potassium concentration. J. Gen. Physiol., 1951, 34, 411.

7. Raker, J. W., Taylor, I. M., Weller, J. M., and Hastings, A. B., Rate of potassium exchange of the human erythrocyte. J. Gen. Physiol., 1950, 33, 691.

8. Love, W. D., and Burch, G. E., Plasma and erythrocyte sodium and potassium concentrations in a group of Southern White and Negro blood donors. J. Lab. \& Clin. Med., 1953, 41, 258.

9. Love, W. D., and Burch, G. E., In vitro studies of aspects of the metabolism of sodium by human erythrocytes using sodium". J. Lab. \& Clin. Med., 1953, 41, 337.

10. Love, W. D., and Burch, G. E., A comparison of potassium ${ }^{2,}$, rubidium ${ }^{80}$, and cesium ${ }^{12}$ as tracers of potassium in the study of cation metabolism of human erythrocytes in vitro. J. Lab. \& Clin. Med., 1953, 41, 351.

11. Solomon, A. K., The permeability of the human erythrocyte to sodium and potassium. J. Gen. Physiol., 1952, 36, 57.

12. Ponder, E., Anomalous features of the loss of $\mathrm{K}$ from human red cells: Results of extended observations. J. Gen. Physiol., 1951, 34, 359.

13. Harris, E. J., Linkage of $\mathrm{Na}$ and $\mathrm{K}$ transport as a basis for the interpretation of the kinetics of movement of these ions between human erythrocytes and the suspension medium. Biochem. J., May, 1953, 54, xiv.

14. Wilbrandt, W., A relation between the permeability of the red cell and its metabolism. Trans. Faraday Soc., 1937, 33, 956.

15. Harris, E. J., and Maizels, M., The permeability of human erythrocytes to sodium. J. Physiol., 1951, 113, 506.

16. Taylor, I. M., Weller, J. M., and Hastings, A. B., Effect of cholinesterase and choline acetylase inhibitors on the potassium concentration gradient and potassium exchange of human erythrocytes. Am. J. Physiol., 1952, 168, 658.

17. Eckel, R. E., Effect of fluoride on potassium transfer in human erythrocytes in vitro. Federation Proc., $1953,12,317$.

18. Sheppard, C. W., and Beyl, G. E., Cation exchange in mammalian erythrocytes. III. The prolytic effect of $x$-rays on human cells. J. Gen. Physiol., 1951, 34, 691.

19. Cooke, R. E., and Segar, W. E., A proposed mechanism of extracellular regulation of muscle composition. Yale J. Biol. \& Med., 1952, 25, 83. 